\title{
Religião, enfrentamento e cura: perspectivas psicológicas
}

\section{Religion, coping, and cure: psychological perspectives}

\author{
Geraldo José de PAIVA'
}

\begin{abstract}
Resumo
Discute-se, a partir da etimologia da palavra, mas do ponto de vista da Psicologia, o conceito de cura como cuidado e como recuperação da doença, relacionando-o em particular com o enfrentamento religioso, forma específica de cuidado consigo e com outrem. Distinguem-se várias possíveis relações entre cura e religião, que determinam o sentido da pergunta de Pargament acerca da singular eficácia do enfrentamento religioso na cura da doença. Defende-se que a Psicologia, como ciência empírica, não é competente para se pronunciar quanto à eficácia do religioso no enfrentamento, embora o possa fazer quanto à eficácia do sagrado. Reconhecem-se, daí, competências diversas ao psicólogo, ao teólogo e ao agente pastoral.
\end{abstract}

Unitermos: cura; enfrentamento religioso; psicologia da religião.

\begin{abstract}
The concept of cure, as care and as recovery from illness, is discussed according to its etymology from a psychological perspective especially in relation to religious coping, which is a particular manner of care. Several possible relations between cure and religion are distinguished and frame out the meaning of Pargament's question about the unique efficacy of religious coping in the cure process. It is argued that psychology, as an empirical science, is unable to assess the religious coping efficacy, although it may do about the sacred efficacy. Diverse competences are, therefore, acknowledged to psychologists, theologians and pastoral agents.
\end{abstract}

Uniterms: cure; religious coping; psychology of religion.

Um antigo provérbio latino dizia medicus curat, Deus sanat, isto é, o médico cura, Deus sara. Se o médico cura, ainda haverá lugar para Deus sarar?

Uma reflexão psicológica acerca das relações entre religião, enfrentamento e cura poderia começar pela etimologia da palavra cura. Curar, em latim, significa literalmente "cuidar". Muitos termos do português conservaram esse sentido literal: curador, curatela, curioso. Outros termos há, como procurar, descurar, segurar (de se-curus, sem cuidado), que literalmente significam cuidar de alguma coisa ou estar dela descuidado.

Sem dúvida, no caso da saúde e da doença o verbo curar/cuidar é muito apropriado. Cuidar da saúde, por exemplo, sugere atenção com a saúde antes da instalação da doença. Cuidar da doença, ou do doente, significa ter cuidado para a saúde não se deteriorar ou o doente não piorar.

Como o resultado do cuidado é muitas vezes o retrocesso da doença e a melhora do organismo, curar,

rery

1 Universidade de São Paulo, Instituto de Psicologia, Departamento de Psicologia Social e do Trabalho. Av. Prof. Mello Moraes, 1721, 05508-020, São Paulo, SP, Brasil.E-mail: <gjdpaiva@usp.br>. 
curar-se, passou, por metonímia, a significar sarar. "Eu me curei" atualmente não quer dizer "eu me cuidei", mas "eu sarei". Quando se diz que o médico cura, geralmente se entende que ele consegue fazer a pessoa sarar. 0 remédio cura porque contribui para que o organismo reaja e se recupere. Aplica-se um curativo não simplesmente porque se cuida de uma ferida, mas porque se aplica um elemento ativo que contribui para a reação restauradora do organismo. A cura, então, pode ser entendida como cuidado e como resultado desse cuidado, a recuperação da saúde.

O conhecimento moderno aí está para esclarecer que a saúde se recupera com os cuidados higiênicos, alimentares e outros que se prestam ao enfermo, e que a doença é impedida com os cuidados que se prestam à saúde. Nesse sentido, tanto a remediação como a prevenção são formas de cuidar ou de curar.

Há um estudo notável do sociólogo da religião Rodney Stark, "O crescimento do cristianismo" (The rise of Christianity) (Stark, 1997), com o subtítulo "como o obscuro e marginal movimento de Jesus tornou-se, dentro de poucos séculos, a força religiosa dominante no mundo ocidental". Segundo Stark, uma poderosa razão da mortalidade dos pagãos, da sobrevivência dos cristãos e da conversão dos pagãos ao cristianismo foi a maneira de os cristãos e os pagãos, respectivamente, cuidarem ou deixarem de cuidar de seus doentes por ocasião das grandes epidemias que assolaram o império romano nos primeiros séculos da era cristã. A caridade, ou seja, o amor ao próximo induziu os cristãos, diferentemente dos pagãos, a providenciar para os irmãos de fé cuidados elementares, como "simples provisão de comida e água que permitem aos temporariamente enfraquecidos lutar por si mesmos pela recuperação em vez de perecer miseravelmente" (McNeill, 1976, citado em Stark, 1997, p.88). Esse cuidado, segundo Stark, não só preservou proporcionalmente muito mais vidas de cristãos do que de pagãos como encaminhou conversões de pagãos ao cristianismo.

Como cuidado, a cura pode suscitar a indagação do porquê e pode ser encarada pela Psicologia como um comportamento motivado. A variável motivadora ora é a pressão grupal para a coesão e a sobrevivência do pequeno grupo, ora o altruísmo que leva alguém a se sacrificar pelo bem do outro, ora um senso de dívida outras mais. Para a Psicologia da religião, no caso do cristianismo, a motivação é impregnada pelo valor da caridade e da fraternidade.

Não há dúvida de que na história do cristianismo, ontem e hoje, o cuidado pelos enfermos é uma das manifestações mais patentes de sua presença no mundo. Se, muito em função do desconhecimento geral no campo da saúde, esse cuidado foi, no passado, mais remediativo do que preventivo, hoje, em razão dos novos conhecimentos e de novas sensibilidades, a psicologia em geral e a psicologia da religião apontarão novos ou renovados elementos motivacionais, como responsabilidade social, senso de justiça, direitos da pessoa, respeito ecológico, elementos que adquirem uma dimensão religiosa caso incluam uma intencionalidade religiosa. É, com efeito, a relação com o objeto religioso que torna religiosa uma variável, e não sua categorização em alguma classe especial de comportamentos.

\section{Saúde/doença, religião e cura}

Há numerosos estudos a respeito da correlação entre religião e saúde, religião e doença, religião e cura (Paiva, 1998a). Além da tradicional relação geral entre religião e saúde (Amundsen, 1987; Sullivan, 1987), alguns autores chegam a se perguntar pela existência de um fator religioso na saúde e na doença (Levin \& Schiller, 1987; Piedmont, 1999, para uma discussão não da religiosidade mas da espiritualidade). Outros estudiosos estão interessados com a relação, do tipo que for, entre religião e saúde/doença mental (Pargament, 1997, 2001), paralelamente àqueles que se interessam pela relação entre religião e saúde/doença física (Argyle, 1993; Argyle \& Beit-Hallahmi, 1975; Mclntosh \& Spilka, 1990). Há, contudo, os que acautelam para a falta de uma metodologia realmente epidemiológica, isto é, ampla o suficiente para abarcar longitudinal e transversalmente os entrelaçamentos de religião e doença, capaz de estabelecer a relação ou a ausência de relação entre saúde/doença e religião (Stenger, 2002; Weaver, 2002).

Em evidente conexão com essas discussões, coloca-se a questão da cura pela religião. Note-se que essa questão não é apenas psicológica e médica, mas também teológica. Há religiões essencialmente de cura, como a religião délfica. Há outras, como o budismo, 
em que a cura é desnecessária. E outras, como o cristianismo, consideram a cura às vezes fim em si mesma, embora parcial, e às vezes sinal de outra realidade final.

A psicologia da religião tem de haver-se com essas várias modalidades religiosas: ela não tem uma palavra única para a relação entre religião e cura porque o comportamento religioso é variado em sua significação. Em outras palavras, como as formas religiosas são históricas, a psicologia só se aplicará com competência a uma modalidade religiosa se apreender seu sentido. Numa cultura, por exemplo, em que saúde e doença são consideradas holisticamente extensões da relação com a divindade, como na antigüidade organizada ao redor da religião (Vergote, 2001), a cura só pode ser religiosa, pela definição dos termos.

Numa cultura moderna, em que se reconhece a autonomia dos diversos segmentos da vida individual e social, a saúde e a doença não têm de passar pela definição religiosa ou, se o fazem, é num sentido bastante peculiar. Se tomarmos o caso do cristianismo, encontraremos entendimentos diversos dessa relação na antigüidade e na modernidade. O interessante é que subsistem em geral nas pessoas dimensões antigas e modernas, de modo que idealmente às vezes nos comportamos como pré-modernos, vendo por exemplo na saúde a bênção de Deus e na doença sua punição, e às vezes como modernos, vendo na saúde o resultado de feliz disposição genética, de recursos econômicos e de conhecimento para cuidar da higiene e da alimentação.

E é também interessante que antigüidade e modernidade ainda hoje se encontram no campo das próprias religiões. As religiões assentadas na comunhão com a natureza e com as forças cósmicas e semelhantes tendem a uma visão pré-moderna, que não circunscreve limites às várias áreas da existência. Nessas religiões, a análise psicológica do comportamento religioso ligado à saúde não se poderá basear no pressuposto "moderno" que distingue o aspecto religioso do aspecto da saúde. No âmbito da cultura cristã contemporânea, o caráter moderno revela-se nos estudos predominantemente correlativos entre religião, doença e saúde. Nexos causais tendem a reduzir a distinção entre os vários segmentos da experiência humana, ao passo que nexos correlacionais mantêm, em princípio, essa distinção.
Um bom resumo da situação atual é oferecido por Ellison (1998), coordenador do Simpósio Religião, Saúde e Bem-Estar, no Journal for the Scientific Study of Religion. Ellison registra que "embora os achados empíricos não sejam inequívocos, as resenhas sistemáticas [dos estudos] têm registrado consistentemente que vários aspectos do envolvimento religioso estão ligados a resultados desejáveis da saúde mental" e que "várias investigações recentes, ... usando rigorosos métodos analíticos, também registram efeitos salutares de diversos indicadores de envolvimento religioso numa ampla gama de resultados de saúde física e mental" (1998, p.692).

A explicação desses achados pode ser buscada, do ponto de vista psicológico, na eficácia da religião em promover comportamentos saudáveis e restringir comportamentos nocivos; na influência da religião nos estilos de vida pessoal; na integração e apoio, favorecidos pelos atos religiosos sociais; na intensificação dos sentimentos de auto-estima e de auto-eficácia providos pela religião; no enfrentamento das situações estressantes num quadro de referência religioso e, possivelmente, nas alterações das conexões psiconeuroimunológicas ou neuroendócrinas que afetam os sistemas fisiológicos (Cohen \& Herbert, 1996; Ellison, 1998; Kiecolt-Glaser, McGuire, Robles \& Glaser, 2002).

\section{A discussão psicológica da cura pelo enfrentamento religioso}

Um dos enfrentamentos possíveis da situação das doenças física e mental, ao lado do profano, ou secular, é o enfrentamento religioso (Pargament, 1997), que utiliza recursos da ordem religiosa para entender a doença e lidar com ela. Freqüentemente as urgências pessoais ou situacionais são enfrentadas pelas pessoas, ao menos em parte, com o recurso religioso de orações, promessas, peregrinações, exercícios ascéticos e ações rituais, conforme as várias religiões, inclusive cristãs. No cristianismo, em particular, uma das manifestações mais indicativas da presença do reino de Deus foram as curas físicas e algumas curas que hoje chamaríamos de psíquicas ou de psicossomáticas, curas essas muitas vezes solicitadas pelo doente ou por outras pessoas. É notável que essas curas geralmente não terminavam no bem-estar físico ou psicológico, mas apontavam para 
um tipo de bem-estar religioso, concretamente a libertação do pecado e a união com Deus.

A pergunta "Será possível à Psicologia estabelecer a existência e a eficácia do enfrentamento religioso?" tem como ponto de partida o reconhecimento, por parte de Kenneth Pargament (Pargament, 1996), do extraordinário poder da religião, que o levou a indagar "se a religião não acrescenta ao enfrentamento algo além do que é fornecido pelo mundo secular" (Pargament, 1996, p.231). Ele cita, com efeito, alguns estudos que demonstram efeitos singulares do enfrentamento religioso. Um exemplo é o seu estudo realizado em 1990, que evidenciou a diferença, pequena mas estatisticamente significante, no comportamento de esquiva segundo a utilização do enfrentamento profano ou do enfrentamento religioso (Pargament et al., 1990).

Nesse estudo, o enfrentamento secular levou a uma esquiva que apenas desviou a atenção de pensamentos penosos, ao passo que o enfrentamento religioso conferiu sentido, estabilidade e conforto. Pargament se pergunta em que consiste a singularidade do enfrentamento religioso e responde com duas ordens de argumento. No artigo de 1990 apela para a versatilidade das religiões que as faz "adaptar-se às mudanças do tempo, das circunstâncias e das necessidades" exatamente graças a seu "caráter abstrato, simbólico e misterioso" (Pargament, 1990, p.205). O caráter protéico e não trivial da religião tornaria possível recorrer a ela em qualquer situação. Em texto posterior, de 1996, apela ao que denomina "a característica mais singular" das religiões, isto é, o sagrado. Do sagrado detalha alguns componentes:"ligação com os antepassados, mistério, sofrimento, esperança, finitude, entrega, propósito divino, redenção" (Pargament, 1996, p.232), e propõe que o sagrado, em virtude de não se subordinar a nenhuma finalidade psicológica ou social, confere à pessoa religiosa um entendimento e uma capacidade de reação peculiares frente aos acontecimentos que fogem a seu controle.

Como ciência moderna, a Psicologia tem estabelecido como seu objeto os fenômenos que ocorrem na faixa da realidade humana situada entre o puramente lógico e o puramente biológico, ou seja, o 102 psíquico, e tem avançado no entendimento desse objeto com conceitos, modelos e métodos próprios. No caso do enfrentamento, a psicologia tem buscado interagir com disciplinas biológicas, como a fisiologia e a psiconeuroimunologia, e com disciplinas sociais, como a antropologia.

Quando se depara com o comportamento religioso utilizado em situações de urgência pessoal e social, a Psicologia, em virtude de seus próprios princípios, está autorizada a emitir um juízo acerca do comportamento, da motivação e da eficácia desse comportamento. Se, como ciência empírica moderna, a Psicologia se abstém de incluir qualquer transcendência em seus pressupostos epistemológicos e metodológicos, penso que Ihe escapa pronunciar-se acerca do propriamente religioso do comportamento. Desse ponto de vista, não penso que Ihe seja possível responder à pergunta de Pargament relativa a uma eficácia distinta da eficácia secular alcançada pelo enfrentamento religioso. Em outras palavras, parece-me uma pergunta mal situada. Não se negam os resultados das pesquisas que apontam uma eficácia diferente e superior do enfrentamento religioso (Pargament, 1990), mas nega-se a possibilidade de a Psicologia alcançá-lo em sua qualidade religiosa. A Psicologia deverá contentar-se, como ciência secular, com uma avaliação secular do enfrentamento religioso. Segundo Aletti (2004), não se trata de perguntar se Deus ajuda, mas se crer em Deus ajuda. Esclareça-se que o crer a que Aletti se refere não é o crer religioso, mas o crer psíquico.

Penso que o problema de Pargament surgiu, quase inevitavelmente, da população estudada, a saber: norte-americanos ligados à cultura moderna do cristianismo. Em parte reagindo à delimitação dessa cultura e em parte suspeitando de um enquadramento mais amplo possível para sua questão, Pargament se refere ao conceito de sagrado como capaz de explicar a singularidade do enfrentamento religioso (Pargament, 1990, 1996). Seria o sagrado que faria a procura religiosa da significância, isto é, do sentido e da relevância, peculiar e potencialmente tão poderosa? Se a pessoa, em outras palavras, consegue dar ao evento que a aflige uma significação e uma importância garantidas pelo sagrado, ela certamente haure um sentido novo e uma força sobre-humana. 
Em parte podemos reconhecer tal explicação como boa. Pargament (1996), entretanto, parece atribuir ao sagrado características de ordens diversas: fim em si mesmo, ligação com os antepassados, mistério, esperança, finitude, entrega, propósito divino, redenção. Algumas dessas características são propriamente sagradas, outras são religiosas, de fato cristãs. A ligação com os antepassados, o mistério que envolve o sofrimento e a finitude e um fim não subordinado a finalidades psicológicas ou sociais são qualificações do sagrado que se pode descrever como o domínio transicional entre o mundo profano e o Deus da religião (Vergote, 1974, 1997). Mas propósito divino, redenção e, nesse contexto, esperança parecem claramente qualificações religiosas, que apontam para o Deus cristão. Enquanto, pois, Pargament situa-se no terreno do sagrado, acredito que ele permaneça no território do empírico, do natural, embora de grande profundidade, que a Psicologia como ciência pode alcançar (Vergote, 1997).

Certamente, as pessoas cujo enfrentamento "religioso"tem a natureza de um enfrentamento"sagrado" mobilizam cognições, motivações, pulsões que dispõem uma nova configuração da existência e podem atingir, mediante o sistema imunológico, a faixa do biológico no homem. Penso que as religiões naturais e, até certo ponto, as religiões da palavra embutidas num sistema de pré-modernidade ensejam o recurso ao sagrado e podem, por isso, ser objeto de um juízo psicológico, inclusive quanto a sua eficácia singular. $\mathrm{O}$ enfrentamento propriamente religioso, ao contrário, penso que escape do alcance do olhar psicológico. O juízo da eficácia desse enfrentamento será da alçada de quem administra a realidade religiosa como tal.

Subjacente a essa discussão está, naturalmente, a conceituação de sagrado, profano e religioso (Paiva, 1998b; Paiva et al., 2004). Sagrado não apenas se contrapõe a profano, desde a definição de Durkheim (Durkheim, 1960/1912; Eliade, s/d), mas também a religioso. Pode-se dizer, em substância, que o sagrado, como substantivo, designa"realidades que representam valores essenciais e ideais, das quais o homem se vê beneficiário e garante". Essas realidades "comportam o interdito de transgressão, porque sua violação destruiria o próprio sentido de existência solidário desses valores" (Vergote, 1974, p.475).
Essas realidades são percebidas como inerentes ao mundo e reveladoras de um mistério (Vergote, 1997). Em comparação, por meio do diferencial semântico com o Deus cristão, o sagrado é percebido na dimensão de profundidade, ao passo que Deus é percebido tanto na dimensão de profundidade como na de altura. Associações com profundidade são, por exemplo,"tocar no que temos de mais pessoal, íntimo, secreto; revelar ao homem seu valor único; invadir todo o ser; ser encontrado quando o homem entra em si; fazer aceder à autenticidade, fonte e origem; dar seriedade e peso às coisas; enraizar-se nas forças vitais; mistério". Associações com altura são, entre outras, ligações positivas com "força, excesso, potência, soberania, majestade, dominação, sublimidade, fascínio, glória, admiração" (Vergote, 1997).

Percebe-se, pois, o sagrado como realidade essencialmente humana mas aberta, o que Ihe dá o caráter de "domínio transicional" (Vergote, 1974) para o religioso, percebido como transcendente à realidade humana. Com base nesse entendimento, foi possível atribuir ao sagrado de Pargament não só grande profundidade psicológica e transicionalidade para o religioso como o status de objeto da ciência psicológica. Esse mesmo entendimento, todavia, levou a manter fora do alcance da Psicologia certas características por Pargament atribuídas ao sagrado, que se revelaram características propriamente religiosas. A questão da eficácia do enfrentamento religioso da doença é deslindada segundo essas orientações conceituais.

Tanto teórica como profissionalmente a não distinção entre religioso, sagrado e profano tem conduzido a mal-entendidos. Tem-se colocado a religião sob a Psicologia ou a Psicologia sob a religião, de alguma forma à revelia da consciência moderna. Há religiosos que enxergam o pecado na raiz de toda doença e, como religiosos, habilitam-se a atender dinâmicas psicológicas. Há psicólogos que não reconhecem autonomia à religião, e identificam o religioso com o psíquico, freqüentemente patológico. E felizmente há os que fazem as distinções, adquirem as respectivas competências ou respeitam em outrem a competência que não possuem, na Psicologia ou na religião. Dessa última forma, será possível aos religiosos continuar usando os recursos do enfrentamento religioso, aos religiosos e aos não religiosos usar os 
recursos do enfrentamento sagrado, aos teólogos e pastores discriminar a adequação do comportamento religioso e aos psicólogos ajuizar da adequação psíquica do comportamento, religioso ou não.

Para concluir, penso que a questão da eficácia singular do enfrentamento religioso como tal não pode ser avaliada pelo psicólogo, embora o psicólogo possa avaliar a eficácia do sagrado, inclusive do sagrado que possibilita no homem a inserção do religioso.

\section{Referências}

Aletti, M. (2004). A representação de Deus como objeto transicional ilusório. Perspectivas e problemas de um novo modelo. In G. J. Paiva \& W. Zangari (Orgs.), A representação na religião: perspectivas psicológicas (pp.19-50). São Paulo: Loyola.

Amundsen, D. W. (1987). Medicine and religion in western traditions. In M. Eliade (Org.), The Encyclopedia of Religion (Vol.9, pp.319-324). New York: MacMillan.

Argyle, M. (1993). The social psychology ofeverydaylife. London: Routledge.

Argyle, M., \& Beit-Hallahmi, B. (1975). The social psychology of religion. London: Routledge \& Kegan Paul.

Cohen, S., \& Herbert, T.B. (1996). Health Psychology: Psychological factors and physical disease from the perspective of human Psychoneuroimmunology. Annual Review of Psychology, 47, 113-142.

Durkheim, E. (1960). Lesformesélémentaires delaviereligieuse. Paris: PUF. (Originalmente publicado em 1912).

Eliade, M. (s/d). OSagrado e o profano. A essência das religiões. Lisboa: Livros do Brasil.

Ellison, C. G. (1998). Introduction to Symposium on Religion, Health and Well-Being. Journal for the Scientific Study of Religion, 27 (4), 692-694.

Kiecolt-Glaser, J. K., McGuire, L., Robles, T. F., \& Glaser, R. (2002). Emotions, morbidity, and mortality: new perspectives from psychoneuroimmunology. Annual Review Psychology, 53, 83-107

Levin, J. S., \& Schiller, P. L. (1987). Is there a religious factor in health? Journal of Religion and Health, 26 (1), 9-36.

Mclntosh, D., \& Spilka, B. (1990). Religion and physical health. The role of personal faith and control beliefs. In D. Moberg \& M. Lynn (Orgs.), Research in the social scientific study of religion, (Vol.2, pp167-194). London: JAI Press.

Paiva, G. J. (1998a). AIDS, Psicologia e religião: o estado da questão na literatura psicológica. Psicologia: Teoria e Pesquisa, 14 (1), 27-34.

Paiva, G. J. (1998b). Estudos psicológicos da experiência religiosa. Temas em Psicologia, 6 (2), 153-160.
Paiva, G. J., Garcia, A., Gonçalves, A. K., Scala, C. T., Faria, D. G. R., Gómez, M. L. T., Jordão, J. P., Barbosa, R. C., \& Franca, S. M. S. (2004). Experiência religiosa e experiência estética em artistas plásticos: perspectivas da psicologia da religião. Psicologia: Reflexão e Crítica, 17 (2), 223-232.

Pargament, K. I. (1990). God help me: toward a theoretical framework of coping for the psychology of religion. In D. Mclntosh, B. Spilka, D. Moberg \& M. Lynn (Orgs.), Research in the social scientific study of religion (Vol.2, pp.195-224). London: The JAI Press.

Pargament, K. I. (1996). Religious methods of coping: resources for the conservation and transformation of significance. In E. P. Schafranske (Org.), Religion and the clinical practice of psychology (pp.215-239). Washington, DC: APA Books.

Pargament, K. I. (1997). The Psychology of religion and coping. Theory, research, practice. New York: The Guilford Press.

Pargament, K. I., Ensing, D. S., Falgout, K., Olsen, H., Reilly, B., van Haitsma, K., \& Warren, R. (1990). Gold help me: (I) Religious coping efforts as predictors of the outcomes to significant negative life events. American Journal of Community Psychology, 18 (6), 793-824.

Pargament, K. (2001). Research suggests correlation between religion and well-being. Research News \& Opportunities in Science and Theology, 1 (11/12), 37.

Piedmont, R. L. (1999). Does spirituality represent the sixth factor of personality? Spiritual transcendence and the five-factor model. Journal of Personality, 67 (6), 985-1013.

Stark, R. (1997). The rise of Christianity. How the obscure, marginal Jesus Movement became the dominant religious force in Western world in a few centuries. San Francisco: HarperCollins.

Stenger, V. J. (2002). Victor J. Stenger on the epidemiology of religion. Research News \& Opportunities in Science and Theology, 2 (5), 26.

Sullivan, L. E. (1987). Diseases and cures. In M. Eliade (Org.), The Encyclopedia of Religion (Vol.4, pp.366-371). New York: MacMillan.

Vergote, A. (1974). Equivoques et articulation du sacré (pp.471-492). Rome: Istituto di Studi Filosofici.

Vergote, A. (1997). Religion, belief and unbelief. A psychologcial study. Amsterdam: Rodopi.

Vergote, A. (2001). Necessidade e desejo da religião na ótica da psicologia. In G. J. Paiva (Org.), Entre necessidade e desejo. Diálogos da psicologia com a religião (pp.9-24). São Paulo: Loyola.

Weawer, A. J. (2002). Research on Religion and Health: a second opinion. Research News \& Opportunities in Science and Theology, 2 (5), 33.

Recebido em: 6/1/2006

Versão final reapresentada em: 9/5/2006

Aprovado em: 24/7/2006 